\title{
Infection Courts and Timing of Infection of Apple Fruit by Phacidiopycnis washingtonensis in the Orchard in Relation to Speck Rot During Storage
}

\author{
P. Sikdar, Department of Plant Pathology, Washington State University, Pullman 99164; M. Mazzola, United States Department of \\ Agriculture-Agricultural Research Service (USDA-ARS), Tree Fruit Research Laboratory, 1104 N. Western Ave., Wenatchee, WA \\ 98801; and C. L. Xiao, USDA-ARS, San Joaquin Valley Agricultural Sciences Center, 9611 S. Riverbend Ave., Parlier, CA 93648
}

\begin{abstract}
Sikdar, P., Mazzola, M., and Xiao, C. L. 2014. Infection courts and timing of infection of apple fruit by Phacidiopycnis washingtonensis in the orchard in relation to speck rot during storage. Plant Dis. 98:1467-1475.

Phacidiopycnis washingtonensis is the cause of speck rot, a recently reported postharvest fruit rot disease of apple. The pathogen is believed to incite infections in the field, and disease symptoms become evident only during storage. To determine the timing of apple fruit infection in relation to development of speck rot in storage, 'Red Delicious' and 'Fuji' apple fruit were inoculated in the orchard with $P$. washingtonensis at different times during the growing season, harvested, and monitored for decay development during storage at $0^{\circ} \mathrm{C}$. Fruit inoculated in both field and laboratory also were used to identify the infection courts and mode of apple fruit penetration by $P$. washingtonensis. In all 3 years, stem-end speck rot and calyx-end speck rot developed during

cold storage on fruit inoculated during the growing season, regardless of inoculation time; and the incidence of total speck rot in storage increased as the fruit inoculation time approached harvest. On fruit floral parts, the pathogen colonized sepals at higher rates than stamens. Availability of naturally occurring necrotic tissues favored the colonization of the fungus on sepals. Histological studies indicated that infection occurred through micro-cracks on the surfaces of pedicels and sepals of the fruit, and invasion of these tissues was restricted between the cuticle and epidermis. Findings of this study will assist in the development of effective control strategies for speck rot.
\end{abstract}

Washington State produces over 50\% of the fresh apples (Malus $\times$ domestica Borkh.) in the United States with a crop value of approximately $\$ 1.83$ billion in 2011 (13). As a large volume of fruit needs to be packed and marketed after harvest, apple fruit may be stored for an extended period of up to 12 months in either regular or controlled atmosphere (CA) ( 1 to $2 \% \mathrm{O}_{2}$ and 0.5 to $1 \% \mathrm{CO}_{2}$ ) at -1 to $4^{\circ} \mathrm{C}(10)$. Postharvest diseases can be a limiting factor for the long-term storage of apple fruit, resulting in millions of dollars in losses each year in Washington State.

Speck rot of apple, caused by Phacidiopycnis washingtonensis C.L. Xiao and J.D. Rogers, is a recently described postharvest disease of apple in the United States (7,23). In a survey conducted in Washington State, $P$. washingtonensis was found to be present in 17 to $26 \%$ of the grower lots (orchards) sampled, but disease incidence was relatively low compared with the incidence of postharvest blue mold, gray mold, and Sphaeropsis rot $(7,8)$. However, in one grower lot examined in 2005, P. washingtonensis caused a $24 \%$ loss of 'Red Delicious' apple fruit that had not been treated with any pre- or postharvest fungicides, demonstrating that this pathogen can result in significant economic loss if it is left uncontrolled (7). P. washingtonensis also causes a twig dieback and can-

Corresponding author: C. L. Xiao, E-mail: Chang-Lin.Xiao@ars.usda.gov

Mention of trade names or commercial products in this article is solely for the purpose of providing specific information and does not imply recommendations or endorsement by the U.S. Department of Agriculture. USDA is an equal opportunity provider and employer.

Accepted for publication 28 April 2014.

http://dx.doi.org/10.1094/PDIS-01-14-0054-RE

This article is in the public domain and not copyrightable. It may be freely reprinted with customary crediting of the source. The American Phytopathological Society, 2014. ker disease in crabapple, which is commonly planted in apple orchards as a source of pollen for apple production in Washington State; and pycnidia of the fungus are often present on diseased crabapple twigs in apple orchards $(22,23)$. In a separate study with apple twigs inoculated with $P$. washingtonensis in the orchard, it was observed that $P$. washingtonensis survives year-round and viable pycnidia on diseased twigs are available during the fruitgrowing season in the orchard, indicating that availability of viable inoculum is unlikely a limiting factor for $P$. washingtonensis fruit infection in the orchard (16). It is believed that $P$. washingtonensis fruit infection occurs in the orchard, and symptoms become apparent only after harvest either during storage or in the market (7). Previous observations indicated that stem-end rot and calyx-end rot are the primary symptoms caused by $P$. washingtonensis on stored fruit. However, rots associated with infections of skin also have been observed on artificially inoculated fruit (7), suggesting that infections are likely initiated at the stem, calyx tissues, or fruit cuticles (skins) leading to stem-end rot, calyx-end rot, and skin rot, respectively. To date, no research has been conducted to determine actual infection courts of apple fruit by $P$. washingtonensis. Although it is believed that $P$. washingtonensis infects apple fruit in the orchard and remains latent before harvest, initial pathogenicity tests only examined fruit inoculations at 1 or 2 weeks before harvest (7). It remains unknown as to the duration of potential apple fruit infection periods by this fungus through the growing season that may lead to speck rot in stored fruit. A more comprehensive understanding of the relationship between timing of fruit infection in the orchard and development of speck rot in storage would facilitate the development of preharvest fungicide spray programs for effective control of speck rot in stored fruit.

Fruit maturity and availability of susceptible tissues also influence the capacity of latent infection-causing fungal pathogens to successfully infect fruit $(4,5,18)$. The presence of necrotic tissues affects the incidence of calyx-end gray mold in strawberry caused by Botrytis cinerea (14). Association of necrotic tissue with calyx- 
end Phacidiopycnis rot in 'd'Anjou' pear fruit caused by Phacidiopycnis piri has also been reported $(11,20)$. Although a preliminary study indicated that speck rot symptoms can originate from infections at the stem, calyx tissue, and lenticels of the fruit inoculated with $P$. washingtonensis (7), a detailed histological study of mode of penetration and relative susceptibility of necrotic and apparently healthy tissues has not been previously conducted. Information concerning the biology of $P$. washingtonensis, including mode of penetration and infection courts, could be utilized to design specific control strategies or determine the correct timing for application of orchard chemical controls.

The objectives of this study were to (i) determine the timing of apple fruit infection by $P$. washingtonensis in the orchard in relation to the development of speck rot in storage, and (ii) identify infection courts and mode of penetration by $P$. washingtonensis on apple fruit.

\section{Materials and Methods}

Inoculum preparation. A single-spore isolate of $P$. washingtonensis, CLX 2152, which was originally isolated from a decayed Red Delicious apple fruit and also is the living culture of the type specimen of the fungus (23), was used in this study. For preparing inoculum, the isolate was revived from $-80^{\circ} \mathrm{C}$ and grown on potato dextrose agar (PDA; Difco Laboratories, Detroit, MI) in the dark at $20^{\circ} \mathrm{C}$. After 4 days, mycelia were transferred to oat meal agar (OMA; $60 \mathrm{~g}$ of finely ground iron- and zinc-fortified oatmeal [Gerber, Fremont, $\mathrm{MI}$ ], $15 \mathrm{~g}$ of agar in 1 liter of deionized water autoclaved at $121^{\circ} \mathrm{C}$ for $90 \mathrm{~min}$ ). The plates were then incubated under 12-h light/12-h dark at $20^{\circ} \mathrm{C}$, and after 10 days, conidia from oozing pycnidia were streaked on new OMA plates to augment inoculum production. Inoculated plates were sealed with Parafilm and incubated at $20^{\circ} \mathrm{C}$ under 12 -h light/12-h dark for 10 days. Conidia were obtained by scraping off oozing pycnidia into $20 \mathrm{ml}$ of sterile deionized water. Spore concentration was adjusted to $5 \times 10^{5}$ co$\mathrm{nidia} / \mathrm{ml}$ with a hemacytometer. Tween 20 was added to the conidial suspension at a final concentration of $0.001 \%$.

Timing of fruit infection in the orchard in relation to speck rot in storage. Fruit inoculations were conducted during the 2010 to 2012 growing seasons in Red Delicious and 'Fuji' blocks established in 2007 and located at the Washington State University Sunrise research orchard, near Palisades, Douglas County, WA, USA (latitude $47.3 \mathrm{~N}$ and longitude120.1W). The single exception was in 2010, when inoculation experiments were conducted in an adjacent organic Red Delicious block. Fruit inoculation began 3 weeks after petal fall and continued up to 2 weeks prior to harvest at 5- to 6week intervals. In total, four inoculations were carried out annually for Red Delicious and five for Fuji. The inoculation dates were 15 May, 20 June, 24 July, 3 September, and 2 October in 2010; 19 May, 23 June, 29 July, 6 September, and 4 October in 2011; and 19 May, 23 June, 25 July, 7 September, and 5 October in 2012. The October inoculations were for Fuji only. The study employed a randomized complete block design with three replicates per treatment and 40 fruit per replicate for each inoculation date. In 2010, the Red Delicious block was managed using both under-tree and overhead irrigation. For Fuji blocks in all 3 years and Red Delicious blocks in 2011 and 2012, the trees were watered using undertree drip or micro sprinkler irrigation. Insects and weeds were controlled following the recommendations for commercial apple production in the region (3). In the semiarid climate of eastern Washington, apple scab is generally not a concern, but fungicides may be applied for control of powdery mildew. In order to avoid potential fungicide interference with the fruit inoculation studies, no fungicides were applied from petal fall through harvest in the research blocks during 2010 to 2012.

Apple fruit were inoculated using a hand sprayer to wet the entire fruit surface including the stem and calyx of the fruit with the $P$. washingtonensis conidial suspension. Control fruit were sprayed with sterile distilled water. After inoculation, fruit were covered with moistened white plastic bags to keep relative humidity high during incubation. All inoculations were carried out near sunset to avoid high temperature during incubation, and bags were removed after approximately $15 \mathrm{~h}$ incubation. For each cultivar, a small data logger (Watchdog 450, Spectrum Technologies, Inc., Plainfield, IL) was placed inside one of the bags to monitor temperature and relative humidity during incubation.

Red Delicious apple fruit were harvested on 30 September 2010, 4 October 2011, and 3 October 2012. Fuji apple fruit were harvested on 19 October 2010, 25 October 2011, and 23 October 2012. On harvest dates, 40 fruit per replicate were harvested and placed onto sterilized fiberboard apple-trays wrapped in perforated polyethylene bags and stored in cardboard apple boxes at $0^{\circ} \mathrm{C}$ in regular atmosphere. Fruit were monitored for decay development monthly beginning 3 months after harvest and continuing up to 9 months after harvest, and the site of infection on the fruit (stem, calyx, or skin infections) and percentage of fruit with speck rot were recorded at each time point. For fruit exhibiting decay symptoms, isolations of the pathogen were attempted from both diseased and symptomless sites. Thus, for fruit with stem-end speck rot, isolations were made from both the decayed flesh at the stem end and the symptomless calyces. For fruit with calyx-end rot, isolations were made from both the decayed area and the symptomless stem. For isolation from the stems or calyces, pedicel and floral parts were immersed in $0.5 \% \mathrm{NaOCl}$ for $5 \mathrm{~min}$, rinsed three times in sterile distilled water, and air-dried in a laminar flow hood. The pedicels were sectioned into 10 pieces and plated on PDA. Each part of calyx end tissue, i.e., sepal, stamen, and style, was dissected using a sterile scalpel and forceps, and plated on PDA. All isolation plates were incubated for 4 to 5 days at $20^{\circ} \mathrm{C}$ in the dark, and colony development was monitored. The presence of $P$. washingtonensis colonies was determined based on the descriptions of the fungus $(21,23)$.

Fruit infection courts. To determine infection courts on floral parts of the fruit, three replicate trees, with 20 fruit per replicate, were inoculated in the orchard during July and September of 2011 and 2012 on the same dates and in the same manner as described above (separate trees were used for infection courts study). Inoculated fruit of both Red Delicious and Fuji were harvested at 2 weeks postinoculation and examined in the laboratory using the following procedures. From 10 of the 20 fruit per replicate, floral parts (i.e., style, stamens, and sepals) of each fruit were used for reisolation of the fungus. Floral parts were excised and surfacedisinfested with $0.5 \%$ sodium hypochlorite solution for $5 \mathrm{~min}$, washed in sterile water three times, and dried on sterilized paper towels. Each floral part was then plated onto acidified potato dextrose agar (APDA, $39.9 \mathrm{~g}$ of PDA in 1 liter of deionized water and $4 \mathrm{ml}$ of $25 \%$ sterile lactic acid). From the other 10 fruit per replicate, necrotic and non-necrotic portions of sepal tissue were excised using a sterile scalpel under a dissecting microscope and plated separately onto APDA. All plates were incubated at $20^{\circ} \mathrm{C}$ in the dark for 4 to 5 days, and the presence of $P$. washingtonensis colonies was recorded based upon floral part and status of sepal necrosis.

In a separate experiment, Red Delicious and Fuji fruit were collected from the Sunrise orchard in July and September of 2011 and 2012 on the same dates when field fruit inoculation was conducted as described above, and were inoculated in the laboratory a day after the collection. Three replicates with 20 fruit per replicate were used in this laboratory inoculation study. All fruit were surface-sterilized with $70 \%$ ethanol for $1 \mathrm{~min}$, rinsed three times in sterile water, and air-dried. The fruit were inoculated by dipping the calyx end into the conidial suspension of $5 \times 10^{5}$ spores $/ \mathrm{ml}$ of the pathogen for $30 \mathrm{~s}$. Inoculated fruit were placed on muffin trays in a plastic container and covered with layers of moistened sterile paper towel. Each container was enclosed in a moistened plastic bag and incubated in the dark at $20^{\circ} \mathrm{C}$. After $24 \mathrm{~h}$, fruit were dried under a fan for $1 \mathrm{~h}$ and then incubated in containers with moist paper towels at $20^{\circ} \mathrm{C}$ for 15 days. After incubation, necrotic and apparently healthy sepal tissues from 10 of the 20 fruit per replicate were separated, and isolation of the pathogen was attempted by plating these tissues on APDA as described above. For the re- 
maining 10 fruit, sepals, styles, and stamens were plated separately on APDA plates and incubated at $20^{\circ} \mathrm{C}$ in the dark for 4 to 5 days. For each tissue type, the percentage of samples from which the pathogen was reisolated was recorded.

Availability of naturally occurring necrotic tissues on sepals. Studies were conducted to determine the seasonal occurrence of necrotic tissues on sepals of fruit in the orchard. Three replicate trees were randomly selected from the Red Delicious and Fuji blocks in WSU Sunrise research orchard as described above, and 10 noninoculated fruit per replicate were removed from trees and brought to the laboratory. For both Red Delicious and Fuji, healthy fruit were collected on the same dates when fruit inoculation was carried out in June, July, and September of 2011 and 2012 as described above. The number of sepals with necrotic tissues and the percent necrotic area on each sepal were estimated using a dissecting microscope. The average of percent sepals with necrotic tissues and the percent necrotic area on sepals of 30 fruit were calculated at each sampling time.

Histological study of mode of entry. Fruit inoculation. Inoculation was carried out in the same Red Delicious block at the WSU Sunrise orchard to study the mode of $P$. washingtonensis fruit penetration. Apple fruit were inoculated during the months of July and September of 2010 and 2011 on the same dates along with the above described inoculations that were carried out to understand the relationships between the timing of infection in the orchard and speck rot development in storage. In the orchard, 10 trees were selected randomly and 30 fruit per tree were inoculated in the same manner as described above. The inoculated fruit were removed from the trees at $12 \mathrm{~h}, 15 \mathrm{~h}, 24 \mathrm{~h}, 36 \mathrm{~h}, 48 \mathrm{~h}, 72 \mathrm{~h}, 5$ days, 7 days, 15 days, and 30 days postinoculation for microscopic examination.

Inoculation was also carried out in the laboratory on detached fruit at the same stage of maturity as utilized in the orchard inoculations. Sound fruit were collected from the same orchard block on the same dates of fruit inoculation in the orchard and were used for laboratory inoculations with the same replication and design on the following day. Fruit were surface-disinfested with $70 \%$ ethanol for $1 \mathrm{~min}$, rinsed three times with sterile water, and air-dried. Fruit were inoculated with a hand sprayer at the stem and calyx-end until run-off. Inoculated fruit were placed in aluminum muffintrays in plastic containers with $200 \mathrm{ml}$ of sterile water in the bottom to maintain high humidity. All fruit were incubated at $20^{\circ} \mathrm{C}$ for 12 h, 15 h, 24 h, 36 h, 48 h, 72 h, 5 days, 7 days, 15 days, and 30 days postinoculation. The samples were then fixed and prepared for microscopy at each time point following procedures as described below.

Specimen preparation for histological studies. At each time point postinoculation, the stem and all floral parts (stamens, style, and sepals) of the fruit were excised with a sterile scalpel. The samples were fixed in formalin-acetic acid-alcohol (FAA) for at least $12 \mathrm{~h}$ (1). Prior to observation with light microscopy or fluorescent microscopy, the sample fixed in FAA was rehydrated using an ethanol series (1). For light microscopy samples, thin sections were made with a razor blade, and then stained in lacto phenol cotton blue solution for $3 \mathrm{~min}$. Excess stain was gently rinsed with sterile $\mathrm{H}_{2} \mathrm{O}$ and air-dried. The slides were examined under a light microscope. The same section of sample used for light microscopy was then rinsed to remove lacto phenol cotton blue dye completely. The section was stained in aniline blue for $3 \mathrm{~min}$ and excess stain removed. The section was observed using a confocal fluorescent microscope (Zeiss LSM 510 Meta, Carl Zeiss, Germany) at an excitation wavelength of $393 \mathrm{~nm}$ and emission of $560 \mathrm{~nm}$. For environmental scanning electron microscopy (ESEM), thin sections of sample fixed in FAA were made using a sharp razor and then prepared through a rehydration procedure in step-wise ethanol series starting from $90 \%$ ethanol through $10 \%$ ethanol with a 10 min wash at each interval, and then a final wash in sterile deionized (DI) water for $10 \mathrm{~min}$ repeated twice (1). The sections were then stored in DI water at $4^{\circ} \mathrm{C}$ until they were observed under SEM. Fixed samples in FAA were prepared for ESEM no sooner than 1 day before observation and stored at $4^{\circ} \mathrm{C}$ for less than $48 \mathrm{~h}$.
The sections in water were placed on a carbon coated platinum stub and observed directly using an ESEM (FEI Quanta 200, FEI, Hillsboro, OR) at a voltage of $20 \mathrm{KV}$ at the Franceschi Microscopy \& Imaging Center (FMIC), Washington State University, Pullman.

Data analysis. To determine the relationship between timing of fruit inoculation in the orchard (expressed as number of days between inoculation and harvest dates) and postharvest incidence of calyx-end speck rot, stem-end speck rot, and total speck rot after 9 months in storage, linear regression analysis was conducted with SAS PROC REG (Version 9.3.3; SAS Institute, Cary, NC). Harvest date was assigned the value 0 , and the days before harvest were expressed as negative values. To determine whether there was a significant difference in the incidence of stem-end rot and calyxend rot each year, and whether the total percentage of rot was significantly different from year to year, a Student's $t$ test was conducted for the data from each inoculation date with SAS PROC TTEST with $P=0.05$.

Differences in percent recovery data from each floral part were analyzed using SAS PROC GLM with mean separation using Fisher's protected least significant difference (LSD) test with $P=$ 0.05. P. washingtonensis colonization data from non-necrotic and necrotic sepal tissues were analyzed with SAS PROC TTEST with $P=0.05$.

\section{Results}

Relationship between timing of preharvest infection and development of postharvest rot. At harvest, stem-end speck rot and calyx-end speck rot were not observed on fruit in any of the inoculated orchard blocks. Speck rot was not observed on the noninoculated control fruit during cold storage. Symptoms of speck rot became apparent on inoculated fruit during storage 3 months after
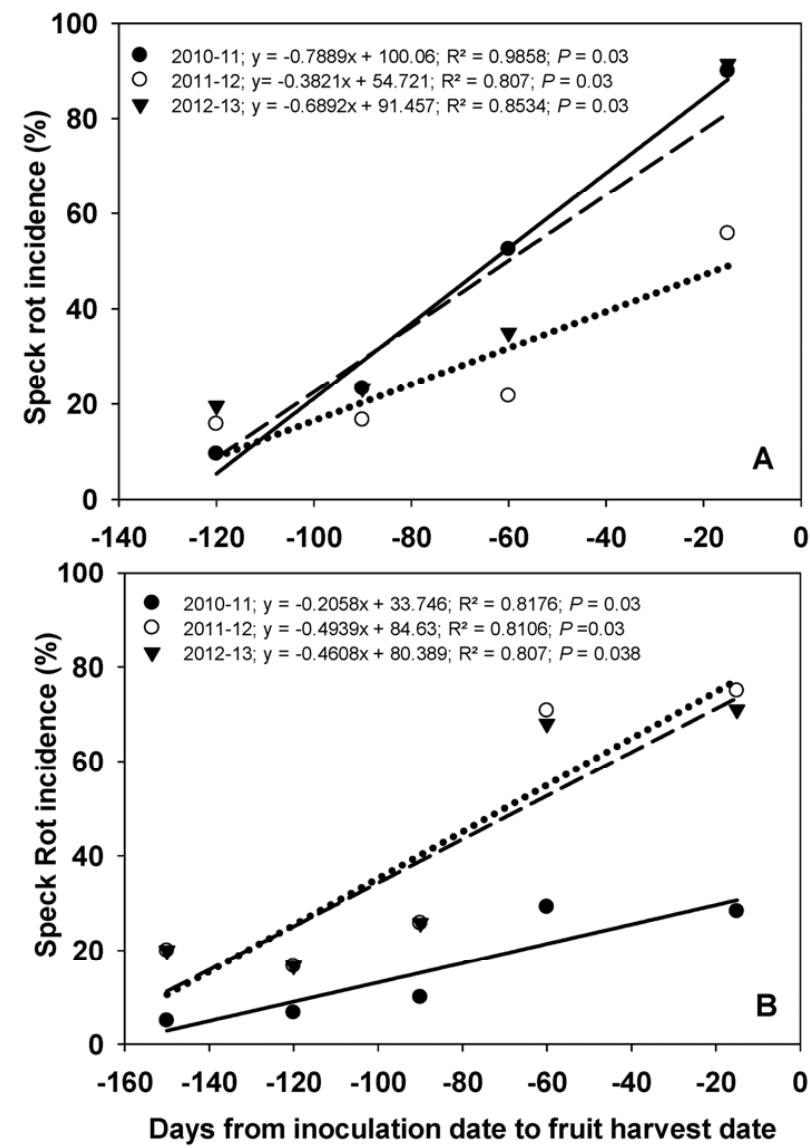

Fig. 1. Relationships between timing of infection of apple fruit in the orchard expressed as days postinoculation to harvest and incidence of speck rot caused by Phacidiopycnis washingtonensis on A, Red Delicious fruit and B, Fuji fruit after 9 months in storage at $0^{\circ} \mathrm{C}$ in $2010-11,2011-12$, and $2012-13$ seasons. Values are means of total percentage of speck rot after 9 months in storage at $0^{\circ} \mathrm{C}$. 
harvest in all 3 years. Speck rot developed on both Red Delicious and Fuji fruit inoculated at any time point during the fruit growing season, and the incidence of speck rot on both cultivars 9 months after harvest increased as the inoculation time in the orchard was closer to the harvest date (Fig. 1). In 2010 to 2011, 90\% of the Red Delicious and $28.3 \%$ of Fuji apples had developed speck rot after 9 months in storage when the inoculation was conducted in September and October 2010, respectively. In 2011 to 2012, 55.8\% of Red Delicious and $75 \%$ of Fuji apples had developed speck rot after 9 months in storage when the inoculation was conducted in September and October 2011, respectively. In 2012 to $2013,91.5 \%$ of Red Delicious and $71 \%$ of Fuji apple fruit had developed speck rot after 9 months in storage when the inoculation was conducted in September and October 2012, respectively.

Stem-end rot and calyx-end rot were the two types of symptoms of speck rot observed on inoculated fruit during storage in all 3 years (Fig. 2). Speck rot initiated from infection of lenticels on the fruit was not observed; however, in some fruit the rot had spread
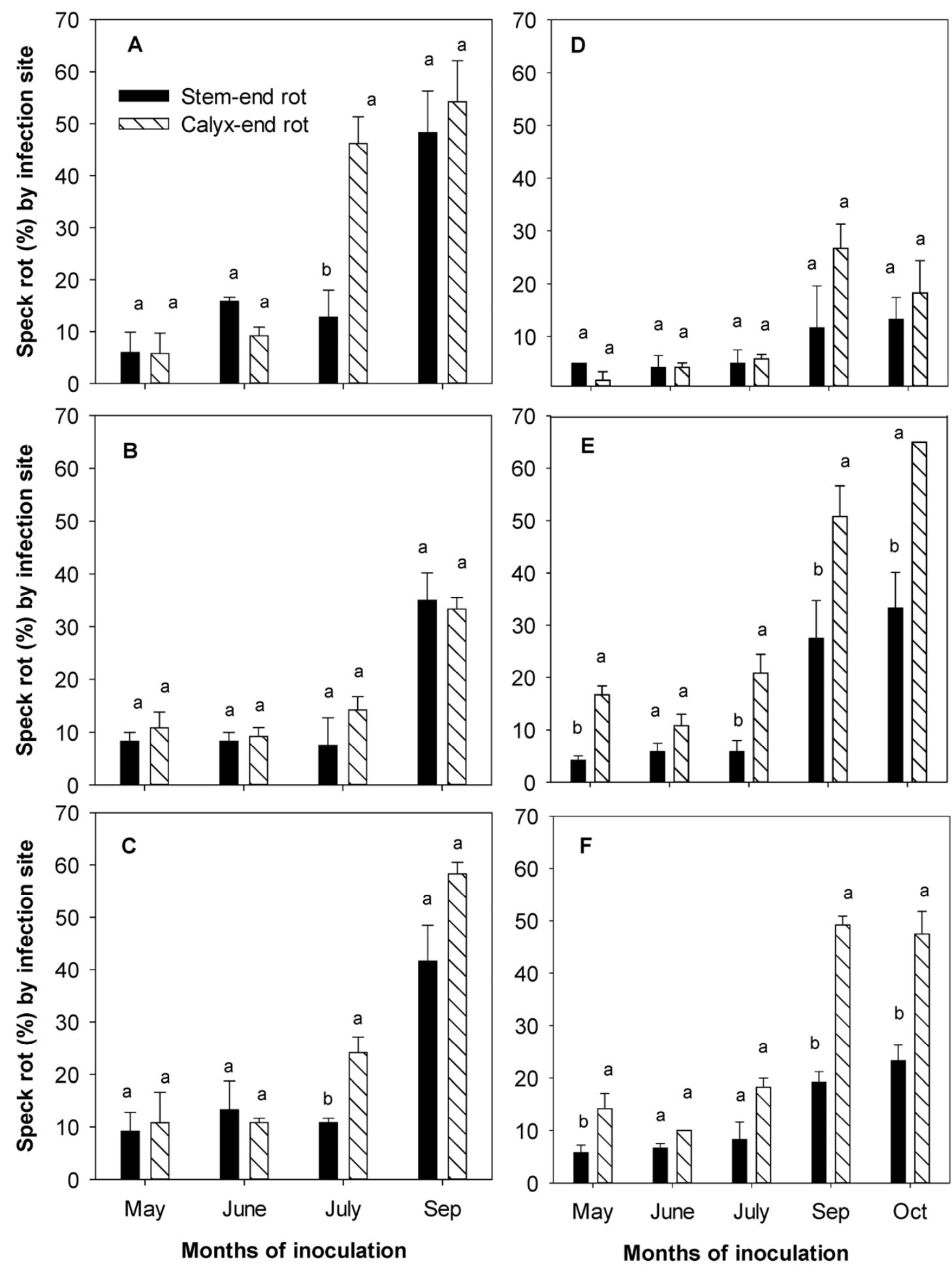

Fig. 2. Incidence of stem-end speck rot and calyx-end speck rot in Red Delicious (A, B, and C) and Fuji (D, E, and F) apple fruit caused by Phacidiopycnis washingtonensis in 2010-11 (A, D), 2011-12 (B, E), and 2012-13 (C, F). Fruit were inoculated in the orchard with a conidial suspension of $P$. washingtonensis, harvested at commercial maturity, and stored at $0^{\circ} \mathrm{C}$ for up to 9 months. Fruit were monitored for the development of speck rot, starting 3 months after harvest up to 9 months in storage. Values with same letter on the top of bars within the same month are not significantly different according to Student's $t$ test $(P=0.05)$. 
across the entire fruit at the time the observations were made, which could have obscured observation of the rot initiation at lenticels. On Red Delicious fruit, there were no significant differences in the incidence of stem-end speck rot and calyx-end speck rot, except for the fruit inoculated in July 2010 and July 2012, on which the percentage of calyx-end rot was significantly higher than that of stem-end rot (Fig. 2A and C). On Fuji fruit, there were no significant differences in incidence of stem-end rot and calyx-end rot in 2010 to 2011 (Fig. 2D), but incidence of calyx-end rot was significantly higher than that of stem-end rot in 2011 to 2012 and 2012 to 2013, except for the fruit inoculated in June 2011 (Fig. 2E) and in June 2012 (Fig. 2F). For the fruit inoculated in July 2012, the incidence of calyx-end rot was higher than that of stem-end $\operatorname{rot}(P=0.055)$.

At each monthly examination of stored fruit starting from 3 months after harvest up to the 9-month period, $P$. washingtonensis was reisolated from the symptomless calyx-end of the fruit exhibiting stem-end speck rot symptoms and reisolated from symptomless stem tissues on the fruit showing calyx-end speck rot symptoms. At the end of the storage period in this study (9 months after harvest), the fungus was isolated from $67 \%$ of Red Delicious and $20 \%$ of Fuji fruit in 2010 to 2011, 23\% of Red Delicious and $56 \%$ of Fuji in 2011 to 2012, and 70\% of Red Delicious and 60\% of Fuji in 2012 to 2013 from the symptomless portion of speck rot-decayed fruit (symptomless stem on calyx-end rot decayed fruit and symptomless calyx on stem-end rot decayed fruit).
Infection courts. $P$. washingtonensis was reisolated from more than $90 \%$ of fruit at 2 weeks postinoculation both in the field and in laboratory experiments, and was recovered from all floral part types (Table 1). However, in both 2011 and 2012 for both Red Delicious and Fuji apple, recovery of the fungus from sepals was significantly higher than that of the style and stamen when inoculations were conducted in the orchard or the laboratory. There was no significant difference in recovery from the style and stamen (Table 1). Regardless of inoculation date, for both cultivars the fungus was present in necrotic sepal tissue to a significantly greater extent than in non-necrotic sepal tissue (Table 2).

Naturally occurring necrotic tissue. Sepal tissues with naturally occurring necrosis were observed on the fruit on all sampling dates during June to September for both apple cultivars. In Red Delicious, the percentages of sepals having necrotic areas in total asymptomatic fruit collected were $8 \%$ in June, $16 \%$ in July, and $46 \%$ in September (near harvest). In Fuji, the percentages of sepals with naturally occurring necrotic areas on the fruit were $5 \%$ in June, $20 \%$ in July, and $43 \%$ in September. The percentage of necrotic area or severity of necrosis on sepals ranged from $10 \%$ in June to $85 \%$ in September for Red Delicious and from $9.5 \%$ in June to $88 \%$ in September for Fuji.

Histological observations of germination and mode of penetration. Germination of conidia was not observed at $24 \mathrm{~h}$ postinoculation (hpi). Conidia of $P$. washingtonensis germinated $48 \mathrm{hpi}$

Table 1. Recovery of Phacidiopycnis washingtonensis from floral parts of Red Delicious and Fuji apple fruit that were inoculated either in the orchard or in the laboratory during July and September of 2011 and 2012

\begin{tabular}{|c|c|c|c|c|c|c|}
\hline \multirow[b]{2}{*}{ Experiment } & \multirow[b]{2}{*}{ Month of inoculation } & \multirow[b]{2}{*}{ Year } & \multirow[b]{2}{*}{ Fruit } & \multicolumn{3}{|c|}{ Percent recovery (\%) } \\
\hline & & & & Sepals & Styles & Stamen \\
\hline \multirow[t]{8}{*}{ Laboratory } & July & 2011 & Red Delicious & $71.6 \mathrm{a}^{\mathrm{z}}$ & $20 \mathrm{~b}$ & $14.5 \mathrm{~b}$ \\
\hline & & & Fuji & $72.7 \mathrm{a}$ & $30 \mathrm{~b}$ & $14.1 \mathrm{~b}$ \\
\hline & & 2012 & Red Delicious & $69.3 \mathrm{a}$ & $33.3 \mathrm{~b}$ & $15.3 \mathrm{~b}$ \\
\hline & & & Fuji & $69.3 \mathrm{a}$ & $33.3 \mathrm{~b}$ & $16.3 \mathrm{~b}$ \\
\hline & September & 2011 & Red Delicious & $78.7 \mathrm{a}$ & $22 \mathrm{~b}$ & $15 \mathrm{~b}$ \\
\hline & & & Fuji & $80 \mathrm{a}$ & $35 \mathrm{~b}$ & $15 \mathrm{~b}$ \\
\hline & & 2012 & Red Delicious & $80 \mathrm{a}$ & $30 \mathrm{~b}$ & $20.8 \mathrm{~b}$ \\
\hline & & & Fuji & $77.3 \mathrm{a}$ & $26.7 \mathrm{~b}$ & $19.2 \mathrm{~b}$ \\
\hline \multirow[t]{8}{*}{ Orchard } & July & 2011 & Red Delicious & $68.7 \mathrm{a}$ & $20 \mathrm{~b}$ & $14.2 \mathrm{~b}$ \\
\hline & & & Fuji & $72.3 \mathrm{a}$ & $20 \mathrm{~b}$ & $14.5 \mathrm{~b}$ \\
\hline & & 2012 & Red Delicious & $65.3 \mathrm{a}$ & $26.7 \mathrm{~b}$ & $17.1 \mathrm{~b}$ \\
\hline & & & Fuji & $66.7 \mathrm{a}$ & $20 \mathrm{~b}$ & $14.5 \mathrm{~b}$ \\
\hline & September & 2011 & Red Delicious & $76 \mathrm{a}$ & $22 \mathrm{~b}$ & $14.5 \mathrm{~b}$ \\
\hline & & & Fuji & $79.3 \mathrm{a}$ & $21 \mathrm{~b}$ & $14.5 \mathrm{~b}$ \\
\hline & & 2012 & Red Delicious & $77.3 \mathrm{a}$ & $26.7 \mathrm{~b}$ & $20 \mathrm{~b}$ \\
\hline & & & Fuji & $72 \mathrm{a}$ & $21 \mathrm{~b}$ & $14.5 \mathrm{~b}$ \\
\hline
\end{tabular}

${ }^{\mathrm{z}}$ Values with the same letter within the same row are not significantly different according to Fisher's LSD $(P=0.05)$.

Table 2. Recovery of Phacidiopycnis washingtonensis from necrotic and non-necrotic sepal tissues of Red Delicious and Fuji apple fruit inoculated with the fungus in the laboratory or in the orchard

\begin{tabular}{|c|c|c|c|c|c|}
\hline \multirow[b]{2}{*}{ Experiment } & \multirow[b]{2}{*}{ Month of inoculation } & \multirow[b]{2}{*}{ Year } & \multirow[b]{2}{*}{ Fruit } & \multicolumn{2}{|c|}{ \% Recovery from sepal tissues } \\
\hline & & & & Necrotic & Non-necrotic \\
\hline \multirow[t]{8}{*}{ Laboratory } & July & 2011 & Red Delicious & $53.3 \mathrm{a}^{\mathrm{z}}$ & $13.3 \mathrm{~b}$ \\
\hline & & & Fuji & $56 \mathrm{a}$ & $12.7 \mathrm{~b}$ \\
\hline & & 2012 & Red Delicious & $61.3 \mathrm{a}$ & $14 \mathrm{~b}$ \\
\hline & & & Fuji & $68 \mathrm{a}$ & $21.3 \mathrm{~b}$ \\
\hline & September & 2011 & Red Delicious & $58 \mathrm{a}$ & $16.7 \mathrm{~b}$ \\
\hline & & & Fuji & $66 \mathrm{a}$ & $20 \mathrm{~b}$ \\
\hline & & 2012 & Red Delicious & $66.7 \mathrm{a}$ & $18 \mathrm{~b}$ \\
\hline & & & Fuji & $72 \mathrm{a}$ & $22.7 \mathrm{~b}$ \\
\hline \multirow{8}{*}{ Orchard } & July & 2011 & Red Delicious & $58.7 \mathrm{a}$ & $13.3 \mathrm{~b}$ \\
\hline & & & Fuji & $60 \mathrm{a}$ & $18.7 \mathrm{~b}$ \\
\hline & & 2012 & Red Delicious & $68 \mathrm{a}$ & $16 \mathrm{~b}$ \\
\hline & & & Fuji & $58.7 \mathrm{a}$ & $16.7 \mathrm{~b}$ \\
\hline & September & 2011 & Red Delicious & $64.7 \mathrm{a}$ & $16.7 \mathrm{~b}$ \\
\hline & & & Fuji & $74 \mathrm{a}$ & $20.7 \mathrm{~b}$ \\
\hline & & 2012 & Red Delicious & $61.3 \mathrm{a}$ & $17.3 \mathrm{~b}$ \\
\hline & & & Fuji & $68.7 \mathrm{a}$ & $19.3 \mathrm{~b}$ \\
\hline
\end{tabular}

\footnotetext{
${ }^{\mathrm{z}}$ Values with the same letter within the same row are no significantly different according to Student's $t$ test $(P=0.05)$
} 
under both laboratory and field conditions on stem and sepal tissues (visualized under SEM, data not shown). The stamen was also examined, but no conidial germination was observed (data not shown). On the stem or sepal tissues, spores began to form small germination pegs at the axis of the spore after 48 to $72 \mathrm{~h}$ for both orchard and laboratory inoculations. However, significant germ tube elongation was not observed until 5 days postinoculation (dpi) (Figs. 3A and 4A and B), and by 7 days extensive growth of the fungus on the epidermal layer was observed on the stem (Fig. 3B and C). Mycelial growth of the fungus on the sepal surface was also observed between 5 and 7 dpi (data not shown). However, the fungus was not observed to initiate penetration via naturally occurring cracks until $15 \mathrm{dpi}$ on both stem (Figs. 3D and 4D and E) and sepal (Fig. 4C and F). No direct penetration of fruit skin tissue by the fungus via the production of an infection peg was noted through $30 \mathrm{dpi}$. Although spores covered anthers when observed by SEM at $7 \mathrm{dpi}$, direct penetration of this tissue by the fungus was not observed through $30 \mathrm{dpi}$.

\section{Discussion}

In this study, we documented that $P$. washingtonensis was capable of infecting the stem and floral parts of apple fruit in the orchard at any inoculation times from 3 weeks after petal fall to near harvest, leading to stem-end rot and calyx-end rot during storage. Fruit inoculated near harvest had higher decay incidence during storage than those inoculated in early season. The absence of rot symptoms on inoculated fruit at harvest suggests that infections remained latent before harvest. Inoculation of the stem and floral parts of apple fruit and microscopy study revealed $P$. washingtonensis was able to colonize the stem and floral parts, particularly sepals of the fruit, resulting in stem-end rot and calyx-end rot, respectively. These results together support that $P$. washingtonensis is a latent fungal pathogen in apple fruit and that the stem and sepals on apple fruit are the main infection sites by $P$. washingtonensis.

The fruit inoculated later in the season (July and September inoculations for Red Delicious, and September and October inoc- ulations for Fuji) had significantly higher incidence of calyx-end rot compared to those inoculated in early season. The increase in calyx-end rot in later season coincided with the increase of sepals with naturally occurring necrotic tissues. As the pathogen appeared to preferentially colonize necrotic sepal tissues, the increased availability of such tissues may facilitate colonization of sepals by $P$. washingtonensis leading to calyx-end rot during storage. Incidence of stem-end rot also was significantly higher on fruit inoculated in September than on those inoculated in the early season for both Red Delicious and Fuji. Both cultivars of apple approach maturity at this time, with Red Delicious being near harvest and Fuji approaching maturity. It is possible that susceptibility of the fruit pedicels to infection by $P$. washingtonensis increased when the fruit approached harvest. A similar observation was made in infection of pear fruit by B. cinerea and Phacidiopycnis piri $(11,19)$ and in infection of prune fruit by Monilinia fructicola (12). Latent infection in apple fruit by Botryosphaeria dothidea and Nectria galligena have been found to be associated with fruit maturity stage and their sugar, amino acid, phenolic and fatty acid content $(9,15)$, and it was found that immature apple fruit were completely resistant to infection by Botryosphaeria ribis through early July (4). These previous studies of the relationship between latent fruit infection and maturity of apple fruit $(4,5,15)$ suggest that antifungal compounds such as phenolics at higher concentrations in immature fruit act to suppress the establishment of latent infections when infection of fruit occurred in the early growing season.

In our study, temperature and relative humidity during the $15 \mathrm{hpi}$ incubation period in the orchard did not appear to limit infection of apple fruit by $P$. washingtonensis. Temperatures maintained within the bags used to cover fruit postinoculation ranged from 10 to $25^{\circ} \mathrm{C}$, which is within the range suitable for conidial germination of the pathogen (23). However, in June 2011 and in July 2010 to 2012, the temperatures inside the bag postinoculation did approach $30^{\circ} \mathrm{C}$. This elevated temperature did not affect the survival of the pathogen, as $P$. washingtonensis was recovered from $90 \%$ of the inoculated fruit sepals. The high temperature recorded inside the
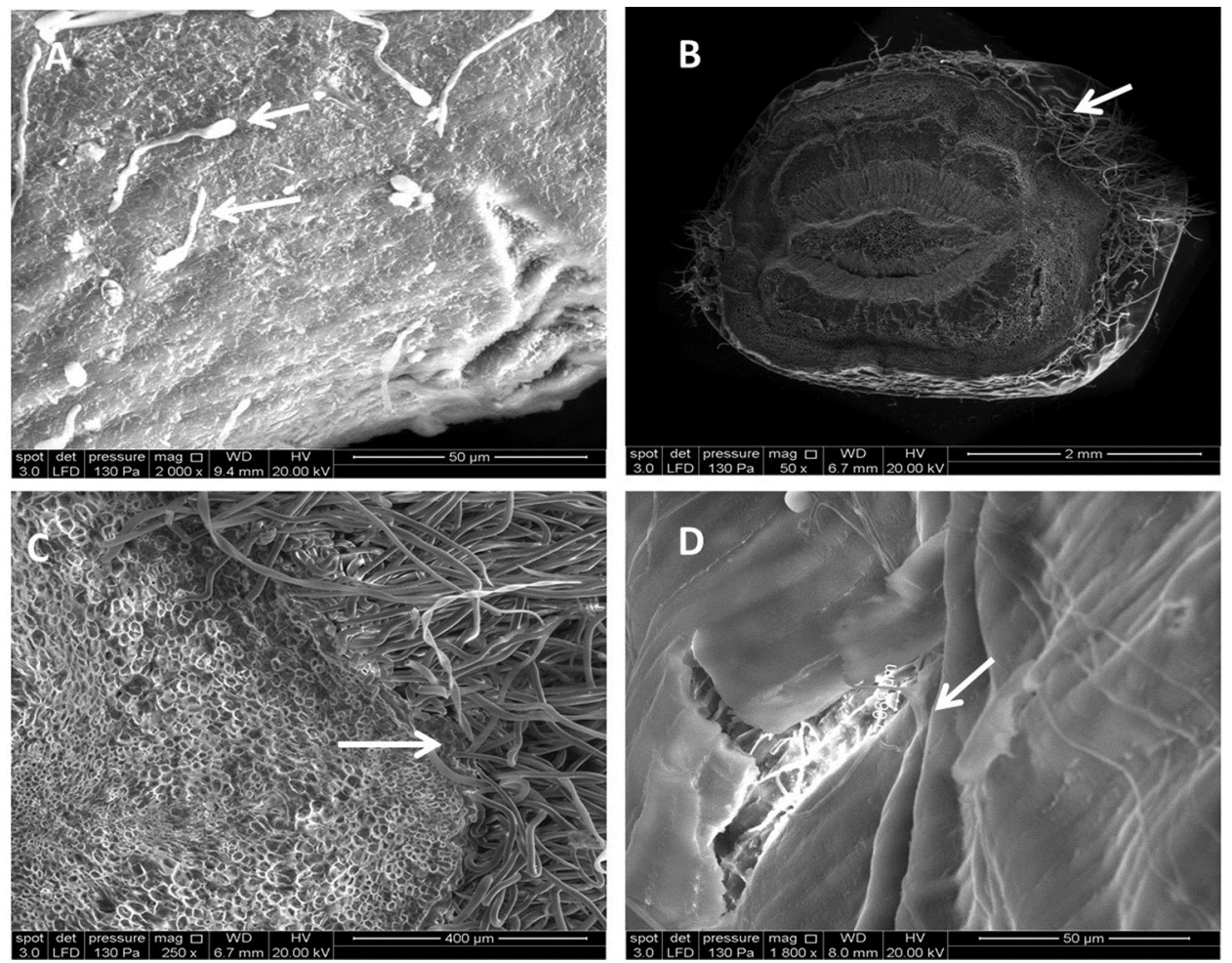

Fig. 3. Micrographs of Field Emission Scanning Electron Microscopy showing germination of Phacidiopycnis washingtonensis conidia on the surface of stem and sepals of inoculated Red Delicious fruit and mode of penetration of the fungal hyphae at various time points post conidial germination. A, Germ tube formation on the stem surface 5 days postinoculation (dpi) with conidia in the laboratory. B, Mycelial growth on the stem surface 7 dpi. C, Magnified $(\times 250)$ view of the stem cross-section of B, showing fungal mycelia at the epidermal layer $7 \mathrm{dpi}$. D, Arrow indicating penetration of mycelia through a natural crack into the upper epidermal layer on cross-section of the pedicel of fruit inoculated in the orchard $15 \mathrm{dpi}$. 


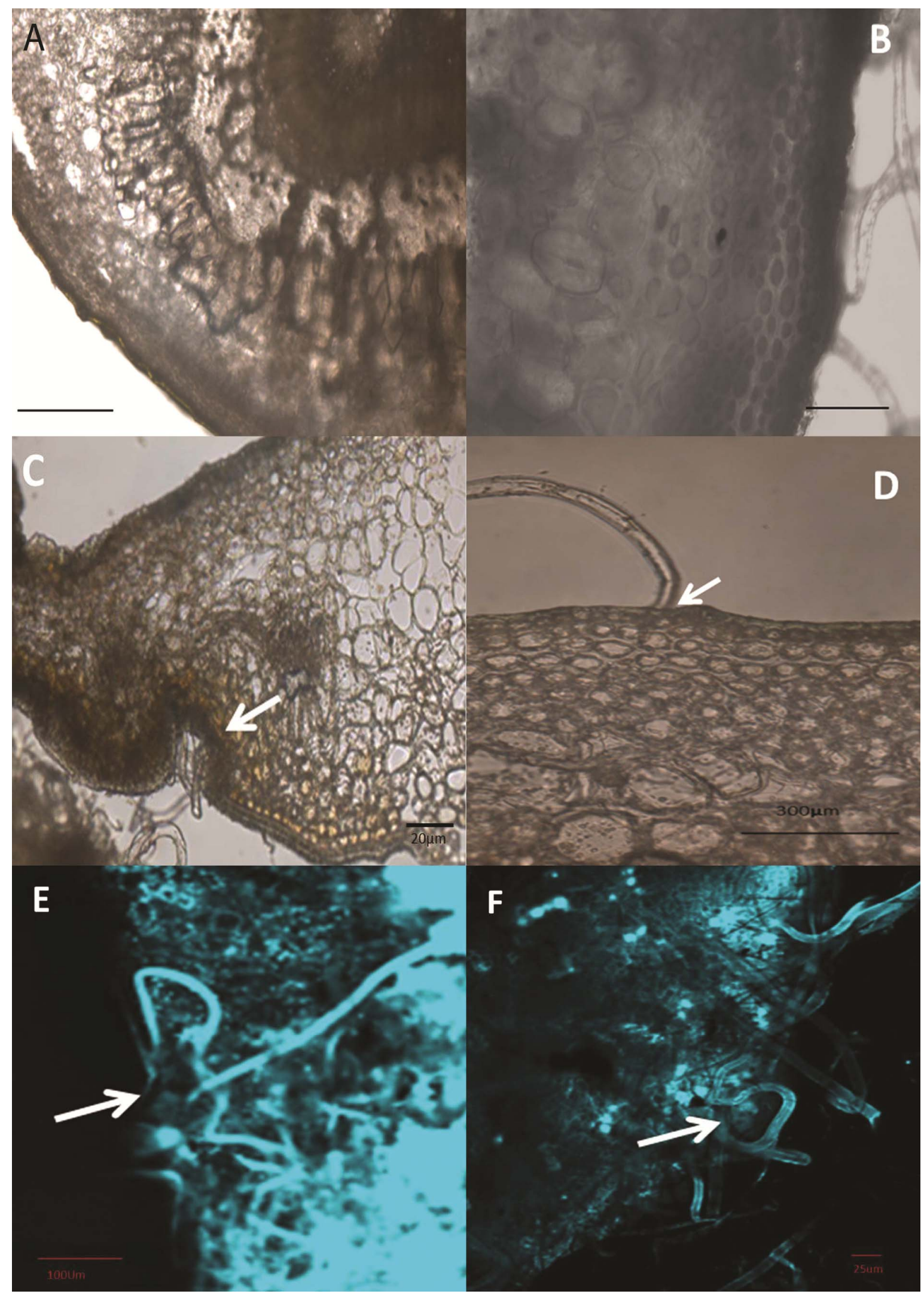

Fig. 4. Phacidiopycnis washingtonensis mycelial growth and mode of penetration in the stem and sepal of apple fruit inoculated in the orchard and in the laboarotory. A to D, Micrographs obtained using light microscopy showing the mode of penetration of $P$. washingtonensis at the stem and sepal of apple fruit stained with cotton blue. A, Stem cross-section $48 \mathrm{~h}$ postinoculation (hpi) where no condia with germ tube visible. B, Stem cross-section 5 days postinoculation (dpi) with mycelia on the surface ( $\times 60$ ). C, Cross-section of sepal $15 \mathrm{dpi}$, arrow indicating mycelial attachment at the upper epidermal layer near the stomatal cavity (×60). D, Stem cross-section at 15 dpi, arrow indicating mycelial attachment at the epidermal layer $(\times 60)$. E and F, Sections were observed under a fluorescence microscope at excitation of $390 \mathrm{~nm}$ and emmission at 560 $\mathrm{nm}$ wavelength. All cross-sections of stem and sepal tissues were stained with aniline blue. E, Cross-section of the stem of apple fruit inoculated, arrow showing penetration of fungal hyphae $15 \mathrm{dpi}$ through the epidermis into upper cortex/hypodermal layers. F, Cross-section of sepal of Red Delicious apple fruit inoculated in the orchard, arrow showing fungal mycelia on the surface at the cuticular layer of sepal $15 \mathrm{dpi}$. 
bag was maintained no longer than $2 \mathrm{~h}$, a duration that likely did not affect the survival of $P$. washingtonensis conidia at the infection site. Low night-time temperatures (between 12 and $15^{\circ} \mathrm{C}$ ) experienced in the fruit incubation bags during September and October appeared to be suitable for infection, as inoculations conducted in September and October resulted in the highest incidence of speck rot in storage.

We observed that speck rot was initiated only at the stem-end and calyx-end of apple fruit. Speck rot originating from infections of fruit skin lenticels was not observed in this study. Our observation is similar to that of Phacidiopycnis rot caused by $P$. piri in d'Anjou pear fruit (11). In contrast to the current study, in a previous study infection at lenticels was observed in stored apple fruit that were inoculated with $P$. washingtonensis 1 and 2 weeks before harvest in the orchard (7). However, the percentage of stem-end (67\% in Red Delicious) and calyx-end rots (68\% in Fuji) were significantly $(P<0.0001)$ higher than infection on fruit skin $(4 \%$ in Red Delicious and $16 \%$ in Fuji) in that study (7). In the present study, fruit were monitored every month and if stem-end speck rot and calyx-end speck rot were observed, the fruit were removed from the storage for reisolation of the pathogen. It is possible that development of visual rot symptoms resulting from lenticel infections required a longer time than those from stem or floral tissue infections; if the storage of the decayed fruit that already showed stem-end or calyx-end rot were extended, symptoms from infections of lenticels on fruit skin might have appeared. Nonetheless, our observations are consistent with previous preliminary observations by Kim and Xiao (7) that the stem and floral parts of the fruit are the major infection sites of apple fruit by $P$. washingtonensis.

$P$. washingtonensis was recovered from all three floral parts of fruit, i.e., sepal, style, and stamen, in fruit inoculation experiments conducted both in the laboratory and in the orchard. However, the recovery from sepals was significantly higher than that from styles and stamens, and recovery from the sepal was often associated with necrotic areas of the tissue. Similar observation was made with regards to $S$. pyriputrescens causing Sphaeropsis rot in apple (6), P. piri causing Phacidiopycnis rot on pear (11), and B. cinerea colonization of the calyx end of strawberry (14). It is believed that pycnidia of $P$. washingtonensis present on diseased twigs or branches of apple or crabapple trees (planted as pollinizers) are the source of inoculum responsible for infection of apple fruit $(16,22)$. In our study, there were no crabapple trees planted as pollinizers in the orchard blocks, no twig dieback or cankers were evident on Red Delicious and Fuji apple trees during the course of experimentation, and speck rot was not observed on noninoculated fruit during storage. Thus, natural inoculum of the pathogen was unlikely present in the orchard blocks, and necrotic tissues on sepals prior to inoculation were presumably not caused by $P$. washingtonensis. The high recovery of $P$. washingtonensis from necrotic tissues on sepals suggests that the fungus preferentially colonized necrotic sepal tissues. Necrotic tissue occurs naturally at the tip of sepals of apple fruit. In the current study, the presence of necrotic sepal tissues was recorded from the early stage of fruit development and increased through fruit maturity, which may explain why the pathogen is detected at a significantly higher occurrence on the sepal. However, the style and stamen could also serves as infection courts because $P$. washingtonensis was reisolated from both of these tissue types.

Histological study indicated that the conidia of $P$. washingtonensis germinated on the stem and sepals of apple fruit under both laboratory and orchard conditions. P. washingtonensis was restricted on the surface of the epidermis of both stem and sepal after conidial germination until 15 dpi. Fungal mycelia were observed to colonize under micro-cracks on the stem after 15 dpi. Light microscopy and fluorescence microscopy indicated that after the pathogen passed through the cracks, the mycelia did not colonize deeper tissue layers and remained latent. Most colonization was restricted to the cuticle and epidermal layer. Similar observation was made in stem-end rot of Florida orange by Diplodia natalensis and Phomopsis citri (2). In the current study, P. washingtonensis was primarily restricted to the surface layer of the apple pedicel and floral parts and did not penetrate deeper layers beyond the epidermis. Our findings suggest that although infections of apple fruit by $P$. washingtonensis may occur anytime during the fruit growing season, application of fungicides near harvest or immediately postharvest prior to storage may help control speck rot.

In conclusion, results from this study indicated that stem and sepal tissues are the primary sites of apple fruit infection by $P$. washingtonensis. In addition, while infection may occur at any time during the fruit growing season resulting in speck rot during storage, infections occurring near harvest resulted in higher incidences of speck rot during storage. As fruit infections by $P$. washingtonensis remain latent at harvest, a rapid and reliable assay for early detection of $P$. washingtonensis in orchards would help in assessing the risk of speck rot in storage and application of appropriate control measures. In a separate study, a real-time PCR assay was developed to detect latent apple fruit infection by $P$. washingtonensis (17). This assay could be used and would help in reducing the time necessary for effective accurate detection of latent infections by the pathogen in the orchard. Controlling postharvest diseases is challenging as fruit are often infected by multiple pathogens. Combining the information from this study along with the real-time PCR assay could enable accurate detection of the causal organism and timely and appropriate management of the disease.

\section{Acknowledgments}

We thank R. Boal, R. Caiazzo, M. Walter, and C. G. Aguilar for assistance with fruit inoculation in the orchard and V. L. Holm for assistance with image acquisition for the SEM micrographs.

\section{Literature Cited}

1. Bombies, K., Shukla, V., and Graham, C. 2008. Scanning Electron Microscopy (SEM) of Plant Tissues. Online. Cold Spring Harbor Protoc. doi:10.1101/pdb.prot 4933.

2. Brown, G. E., and Wilson, W. C. 1968. Mode of entry of Diplodia natalensis and Phomopsis citri into Florida oranges. Phytopathology 58:736739.

3. Bush, M. J., Dunley, J., Beers, E. H., Brunner, J. F., Grove, G. G., Xiao, C. L., Elfving, D. C., Peryea, F., Schrader, L., Parker, R., Smith, T. J., Daniels, C., Maxwell, T., Foss, S. L., Johnson, E., and Tangren, J. 2010. 2010 Crop Protection Guide for Tree Fruits in Washington. Wash. State Univ. Ext. Bull. EB 0419.

4. Hwang, B. K. 1983. Contents of sugars, fatty acids, amino acids and phenolic compounds of apple fruits in relation to their susceptibility to Botryosphaeria ribis. Phytopathol. Z. 108:1-11.

5. Kim, K. W., Park, E. W., Kim, Y. H., Ahn, K.-K., Kim, P. G., and Kim, K. S. 2001. Latency and defense related ultrastructural characteristics of apple fruit tissues infected with Botrosphaeria dothidea. Phytopathology 91:165172.

6. Kim, Y. K., Curry, E. A., and Xiao, C. L. 2014. Infection of apple fruit by Sphaeropsis pyriputrescens in the orchard in relation to Sphaeropsis rot in storage. Eur. J. Plant Pathol. 140:133-143.

7. Kim, Y. K., and Xiao, C. L. 2006. A postharvest fruit rot in apple caused by Phacidiopycnis washingtonensis. Plant Dis. 90:1376-1381.

8. Kim, Y. K., and Xiao, C. L. 2008. Distribution and incidence of Sphaeropsis rot in apple in Washington State. Plant Dis. 92:940-946.

9. Kohn, F. C., and Hendrix, F. F. 1983. Influence of sugar content and $\mathrm{pH}$ on development of white rot on apple. Plant Dis. 67:410-412.

10. Kupferman, E. 2003. Controlled atmosphere storage of apples and pears. Acta Hortic. 600:729-735.

11. Liu, Q., and Xiao, C. L. 2009. Infection of d'Anjou pear fruit by Potebniamyces pyri in the orchard in relation to Phacidiopycnis rot during storage. Plant Dis. 93:1059-1064.

12. Luo, Y., and Michailides, T. J. 2001. Factors affecting latent infection of prune fruit by Monilinia fructicola. Phytopathology 91:864-872.

13. National Agricultural Statistics Service. 2012. Value of Washington's 2011 Agricultural Production Sets Record High. http://www.nass.usda.gov/ Statistics_by_State/Washington/Publications/Current_News_Release/Top 40_2012.pdf

14. Powelson, R. L. 1960. Initiation of strawberry fruit rot caused by Botrytis cinerea. Phytopathology 50:491-494.

15. Seng, J. M., Saindrenan, P., and Bompiex, G. 1985. Induction of Nectria galligena mutants resistant to benzoic acid and study of their aggressiveness towards immature apple. J. Gen. Microbiol. 131:1863-1866.

16. Sikdar, P., Mazzola, M., and Xiao, C. L. 2013. Phacidiopycnis washingtonensis: Inoculum availability, persistence and seasonal host susceptibility in Washington apple orchards. Phytopathology 103:S2.133.

17. Sikdar, P., Okubara, P., Mazzola, M., and Xiao, C. L. 2014. Development of 
PCR assays for diagnosis and detection of the pathogens Phacidiopycnis washingtonensis and Sphaeropsis pyriputrescens in apple fruit. Plant Dis. 98:241-246.

18. Sitterly, W. R., and Shay, J. R. 1960. Physiological factors affecting the onset of susceptibility of apple fruit to rotting by fungus pathogen. Phytopathology 50:91-93.

19. Spotts, R. A. 1985. Effect of preharvest pear maturity on decay resistance. Plant Dis. 69:388-390.

20. Xiao, C. L., and Boal, R. J. 2004. Prevalence and incidence of Phacidiopycnis rot in d'Anjou pears in Washington State. Plant Dis. 88:413-418.
21. Xiao, C. L., and Kim, Y. K. 2008. Postharvest fruit rots in apples caused by Botrytis cinerea, Phacidiopycnis washingtonensis, and Sphaeropsis pyriputrescens. Online. Plant Health Progress doi:10.1094/PHP-2008-0919-01DG

22. Xiao, C. L., Kim, Y. K., and Boal, R. J. 2009. A new canker disease of crabapple trees caused by Phacidiopycnis washingtonensis in Washington State. Online. Plant Health Progress doi:10.1094/PHP-2009-0612-01-BR

23. Xiao, C. L., Rogers, J. D., Kim, Y. K., and Liu, Q. 2005. Phacidiopycnis washingtonensis - a new species associated with pome fruits from Washington State. Mycologia 97:464-473. 